\title{
UM DIÁLOGO EPISTEMOLÓGICO COM FREIRE: PALAVRA, PRÁXIS E EDUCAÇÃO
}

\section{AN EPISTEMOLOGICAL DIALOGUE WITH FREIRE: WORD, PRAXIS AND EDUCATION}

\author{
MACEDO, Eunice ${ }^{1}$ \\ CARVALHO, Alexandra ${ }^{2}$
}

\begin{abstract}
RESUMO
Neste artigo, busca-se estabelecer um diálogo com Freire em torno da sua praxiologia. Partimos da ideia de inacabamento e incompletude do ser humano para uma visão da história como possibilidade, em que se pode criar espaço para a co-laboração através do diálogo com as outras pessoas e mediatizado pelo mundo. Trazemos à colação um conjunto de articulações entre Freire e outros autores bem como estabelecemos pontos de contacto entre o pensamento freiriano e algumas pensadoras feministas, no que concerne a introdução de uma linguagem amiga-do-género e a complexificação do conceito de opressão. Com um enraizamento na palavra, no diálogo e na práxis, exploramos o constructo de uma educação problematizadora e libertadora tendente à humanização dos processos educativos e à acentuação da produção social e cultural. Tem-se em conta, nesta análise, a emergência de contextos sociais em que a opressão e quem é oprimido ganham novos contornos, reclamando uma reconceptualização.
\end{abstract}

Palavras-Chave: Freire; Práxis; Palavra; Educação libertadora; Epistemologia.

\begin{abstract}
In this article, we seek to establish a dialogue with Freire around his praxeology. We start from the idea of the uncompleted and unfinished character of the human being and we move into a view of history as a possibility, in which one can create space for co-laboration through dialogue with other people and mediated by the world. We bring to the fore a set of articulations between Freire and other authors as well as we establish contact points between Freirean thinking and some feminist thinkers, regarding the introduction of a gender-friendly language and the complexification of the concept of oppression. Rooted in the word, dialogue and the praxis, we explore the construct of a problematizing and liberating education, which tends towards the humanization of educational processes and the accentuation of social and cultural production. In this analysis, the emergence of social contexts in which oppression and the oppressed gain new contours, calls for reconceptualization.
\end{abstract}

KeY WORDS: Freire; Praxis; Word; Liberating education; Epistemology.

\footnotetext{
${ }^{1}$ Professora Auxiliar da Universidade do Porto, Faculdade de Psicologia e de Ciências da Educação; Investigadora do Centro de Investigação e Intervenção Educativas (CIIE-FPCEUP); Vice-Presidente da Direção do Instituto Paulo Freire de Portugal (IPFP). e-mail: eunice@fpce.up.pt

${ }^{2}$ Bolsista de Investigação do Centro de Investigação e Intervenção Educativas (CIIE), da Faculdade de Psicologia e de Ciências da Educação da Universidade do Porto. e-mail: alex_carvalho@fpce.up.pt
} 


\section{Primeiras palavras}

Este artigo constitui uma reflexão - em diálogo carinhoso com Freire - acerca da proposta político-pedagógica deste autor, considerado, em muitos contextos, como um dos maiores pedagogos do século XX. O reconhecimento do seu trabalho no campo social e educativo é visível também nas inúmeras edições e reedições dos seus trabalhos, mesmo post mortem, nas contínuas traduções das suas obras, e na emergência, um pouco por todo o mundo, de organizações ligadas à educação e intervenção social que tomam o seu nome e procuram interpretar, recriar e contextualizar o seu ideário, atribuindo maior ou menor dimensão a aspectos específicos da sua proposta. São insólitas assim as fortes manifestações no seu país de origem, agora em estado de profunda conturbação social, e no qual, movimentos hegemónicos responsabilizam ilegitimamente o estado atual da educação no Brasil, segundo estes "doutrinada", pela influência de Freire.

Assumindo, tal como Freire a impossibilidade da neutralidade, e retomando as suas palavras em Pedagogia da Autonomia, "ensinar exige comprometimento". Freire já nos havia advertido para esta "esperteza com que a ideologia dominante insinua a neutralidade da educação" (FREIRE, 1999, p. 109-110), anunciando ele, contrariamente, que na prática pedagógica "não posso ser uma omissão mas um sujeito de opções. Devo revelar aos alunos a minha capacidade de analisar, de comparar, de avaliar, de decidir, de optar, de romper".

É na busca de estabelecimento de diálogo com Freire que, neste artigo, partimos da ideia de inacabamento e incompletude do ser humano para a visão da história como possibilidade, constructo quotidiano em co-laboração através do diálogo com as outras pessoas e mediatizado pelo mundo. Nesse sentido, passamos a referir as desigualdades presentes nesse mundo para argumentarmos em favor da práxis, como relação indissociável entre reflexão e ação, inerente a um paradigma de educação libertadora e problematizadora. Esta constitui condição e forma de luta pela emancipação, sendo através dela que as pessoas se constituem como sujeitos da sua própria libertação.

Tendo vivido entre 1921 e 1997, Paulo Freire deixou um legado extraordinário de dedicação à intervenção com o mundo. Indo para além das teorias da reprodução cultural e social que analisavam a escola como instrumento de reprodução através da transmissão intergeracional, que robustecia e reproduzia "naturalmente" a hierarquização social, Freire situa-se nas teorias da produção cultural e social, localizando a educação como possibilidade emancipatória dos grupos oprimidos. Concretamente na Pedagogia da Autonomia (FREIRE, 1999), Freire recupera o espaço daquilo que se pode designar por uma racionalidade hermenêutica, ao bom modo ricoeuriano, ligada ao emocional e aos afetos, como modo humano de saber (HENRIQUES, 2001) com que Freire faz também a asserção da esperança, não ingénua, no poder humano de transformação. Apelando à necessidade de uma mudança, que sendo difícil é possível e urgente, Freire afirma a necessidade de autoquestionamento face à complexidade de cada ser humano e da realidade que nos circunda, recusa a ideia de pré-destinação e a nossa responsabilidade em 


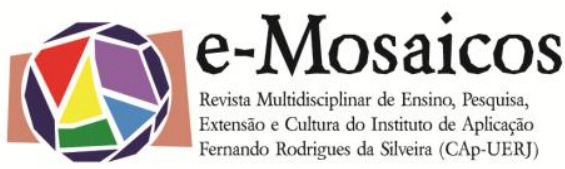

DOI: $10.12957 /$ e-mosaicos.2017.30773

provocar mudança como autores e autoras da nossa história. A História é vista como "tempo de possibilidade", em que cada pessoa, consciente dos constrangimentos de que está rodeada, pode agir para a mudança. Assim afirma,

Gosto de ser gente porque, mesmo sabendo que as condições materiais, econômicas, sociais e políticas, culturais e ideológicas em que nos achamos geram quase sempre barreiras de difícil superação para o cumprimento de nossa tarefa histórica de mudar o mundo, sei também que os obstáculos não se eternizam (FREIRE, 1999, p. 58$60)$.

Evidenciando o sentido de imperfeição e inacabamento do ser humano mas também o gosto de ser 'gente', Freire situa-nos como seres com capacidade e responsabilidade de intervir na vida de todos os dias e de construir, em co-laboração, a História como possibilidade. História que já não é vista numa perspectiva unívoca e de continuidade - paradigma da 'História' que tem vindo a ser contada, dos e pelos grupos dominantes, uma História que atribui a cada um o seu "destino" -, mas uma 'História' outra, como multiplicidade de histórias, com fluxos, refluxos e avanços, História feita de uma voz dos oprimidos, assim empoderada. É nessa linha que Freire faz a asserção da nossa presença no mundo como tarefa de transformação, de desocultação de posições estruturais e dos obstáculos e privilégios a elas inerentes, por meio de uma educação como processo de conscientização. Conceito que alguns autores consideram central a toda a proposta freiriana (ex: MACEDO; VASCONCELOS; EVANS; LACERDA e VAZ PINTO, 2013). É assim que este autor afirma de diversas formas, e ao longo de todo o seu trabalho, que as pessoas "se educam em comunhão, mediatizadas pelo mundo" (FREIRE, 1999, p. 69).

\section{A PALAVRA COMO PRÁXIS}

O trabalho de Paulo Freire, pessoa sensível e crítica, foi fortemente permeabilizado pelas suas experiências de vida. Referiremos algumas dessas vivências para acentuar essa profunda articulação, começando na sua infância. Sobre a "leitura do mundo", por exemplo, diz-nos Freire, na obra intitulada Importância do ato de ler.

Os 'textos', as 'palavras', as 'letras' daquele contexto se encarnavam no canto dos pássaros (...); na dança das copas das árvores sopradas por fortes ventanias que anunciavam tempestades, trovões, relâmpagos; as águas da chuva brincando de geografia: inventando lagos, ilhas, rios, riachos. Os 'textos', as 'palavras', as 'letras' daquele contexto se encarnavam também no assobio do vento, nas nuvens do céu, nas suas cores, nos seus movimentos; na cor das folhagens, na forma das folhas, no cheiro das flores - nas rosas, nos jasmins -, no corpo das árvores, na casca dos frutos (FREIRE, 1999, p. 13). 


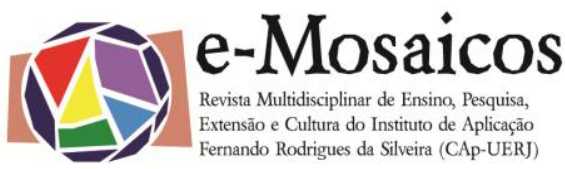

DOI: $10.12957 /$ e-mosaicos.2017.30773

A entrada na escola revelou-se marcante para Freire pela passagem harmoniosa desta "leitura do mundo" - estimulada pelo pai, um espírita sem filiação religiosa, e pela mãe, uma católica convicta - à descoberta da palavra, às vezes feita "palavramundo". Com este neologismo, com que, simbolicamente, Freire constrói a simbiose entre "palavra" e "mundo", se enfatiza a importância da tomada de voz e da alfabetização, não de uma forma mecânica, mas para permitir atribuir e construir significados, "pronunciar" e "anunciar" o mundo.

ao chegar à escolinha (...) já estava alfabetizado. Eunice continuou e aprofundou o trabalho de meus pais. Com ela, a leitura da palavra (...) jamais significou uma ruptura com a 'leitura' do mundo. Com ela, a leitura da palavra foi a leitura da 'palavramundo' (FREIRE, 1999, p. 15).

Este excerto permite, ainda, realçar a importância do encontro entre-culturas de socialização, neste caso cultura familiar e cultura escolar, permitindo também estabelecer relações com a forma como o capital cultural e social (BOURDIEU, 1990), podem ser rentabilizados (ou não) para navegar com sucesso no sistema educativo (ALLARD, 2005). Induz, também, a reflexão sobre a violência simbólica e de recontextualização (BOURDIEU, 1982) de que muitas crianças e jovens são objeto, e ainda sobre a necessidade de reduzir esse problema socioeducativo. Desse modo a entrada e permanência na educação formal deixaria de constituir ameaça para ganhar lugar como espaço de construção coletiva e de realização pessoal. Fala-se, aqui, de uma educação para todas as pessoas que vá para além da massificação para incorporar efetivos princípios de democratização, potenciadores de sucesso educativo e social. Ou seja, uma educação que se liberte dos princípios de uma educação bancária e que, permitindo a tomada de consciência e da palavra, se dirija à diminuição de situações de exploração, marginalização, falta de poder, imperialismo cultural e violência, como educação libertadora e emancipatória, a pedagogia do oprimido como anunciado por Freire. Retomamos esta ideia, com Iris Young, mais adiante.

É nesta articulação reflexiva entre a experiência e os significados individualmente atribuídos e a aprendizagem da capacidade de pronunciar o mundo para transformá-lo com as outras pessoas que constitui a práxis. Deste modo freire desvia-se tanto da ideia de um ativismo em que a necessidade de ação se desvia da reflexão crítica como se desvia daquilo que designa por palavra inautêntica, ou seja uma palavra desligada do intuito transformador. Nesse sentido, a palavra é práxis. Freire afirma a relação indissociável entre ação e reflexão como elementos constitutivos do diálogo, dizendo:

Ação e reflexão [são] de tal forma solidárias, em uma interação tão radical que, sacrificada, ainda que em parte, uma delas, se ressente, imediatamente, a outra. Não há palavra verdadeira que não seja práxis. Daí, que dizer a palavra verdadeira seja transformar o mundo (FREIRE, 1987, p. 77). 


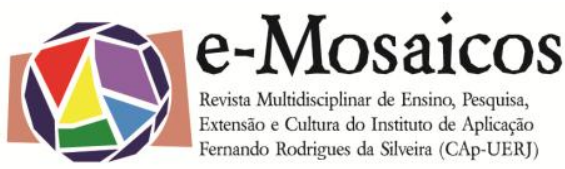

DOI: $10.12957 /$ e-mosaicos.2017.30773

É de notar que o uso da palavra verdadeira não se refere a uma universalização do significado da verdade, mas se refere antes à autenticidade e à intenção transformadora, pela tomada de consciência e ação de superação de situações-limite de opressão em que as pessoas oprimidas se encontram imersas. Servindo para pronunciar 0 mundo a anunciar a mudança, a palavra verdadeira desvia-se dos mitos legitimadores que servem à manutenção, pelos grupos dominantes, do status quo. O diálogo ganha vez como condição para que a mudança aconteça no quadro de uma educação humanista-libertadora. Como dialogicidade, o diálogo é dialético-problematizador, permitindo compreender a dimensão processual inerente ao mundo e à existência humana, implicando portanto uma práxis social, comprometida com a sua transformação (ZITKOSKI, 2015). A dialogicidade torna-se assim crucial para uma "educação problematizadora, enquanto um quefazer humanista e libertador (...) em que os homens [e mulheres] submetidos à dominação, lutem por sua emancipação (FREIRE, 1987, p. 75).

Nesta linha, os textos de Freire enfatizam uma construção social sustentada na ação e reflexão, através do diálogo dialético-problematizador. Esta práxis, que liga mundo experiencial e educação, surge mais numa perspetiva de escuta e incorporação da diversidade das vozes que se cruzam no interior do campo educativo. A práxis de que fala Freire (1987) corresponde a uma ação de reflexão desenvolvida no ato de construção da história, e é com base nessa práxis que as pessoas criam cultura e sociedade, tornando-se sujeitos criticamente conscientes e transformadores. Essa consciência advém de uma articulação dialética entre o particular e o global.

Consciente dos limites macroestruturais, Freire faz a proposta de uma Pedagogia do Oprimido assente na conscientização e na dialogicidade permanente na ação. Essa conscientização faz-se através da inserção crítica dos seres humanos na realidade através da práxis, tendente à construção de uma ação deliberada e transformadora. Assim a pedagogia freiriana, que tem como objetivo permitir às e aos oprimidos pronunciar o mundo, isto é, tomar a voz, no sentido da humanização, ganha corpo na tentativa de restaurar uma intersubjetividade humanizadora. Nesse sentido, assenta, em primeiro lugar, na mudança da perceção do mundo e no compromisso com a sua transformação e, posteriormente, na expulsão dos mitos legitimadores. Isto permite alargar a Pedagogia do Oprimido também às e aos opressores, como referia Freire (MACEDO; VASCONCELOS; EVANS; LACERDA e VAZ PINTO, 2013), ultrapassando o binómio opressor/oprimido e repensando a complexidade destas posições. Como refere Freire, o oprimido contém em si o opressor. Admite-se também que o opressor contenha em si o oprimido (MACEDO, 2009). Neste enquadramento, como acentuam Rosiska Darcy de Oliveira e Miguel Darcy de Oliveira (1982) salienta-se a importância do apelo de Stavenhagen, já nos anos 1970, há necessidade de as Ciências Sociais, e o conhecimento em geral, privilegiarem também

como objeto de estudo, o outro pólo da relação de dominação, com vista a estudar os grupos dominantes e os mecanismos 


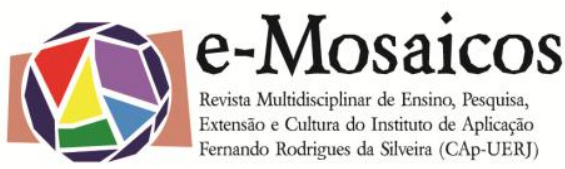

DOI: $10.12957 /$ e-mosaicos.2017.30773

pelos quais eles asseguram a manutenção de seus monopólios sobre o saber e o poder (OLIVEIRA e OLIVEIRA, 1982, p. 21).

A mesma ordem de razão é aplicável aos níveis macro, meso e micro. Situando-nos no campo educativo e da prática educativa, na linha de Freire, se se entende que a educação, só por si, não pode mudar o mundo, também é sabido que esta tem um papel crucial na ação problematizadora, transformadora e libertadora, cabendo

a educadoras e a educadores progressistas, armados de clareza e decisão política, de coerência, de competência pedagógica e científica, da necessária sabedoria que percebe as relações entre tácticas e estratégias não se deixarem intimidar (FREIRE, 1993, p. 100).

No ponto seguinte, fazemos a articulação entre pontos nodais na vida de Freire, acentuamos algumas das influências no seu pensamento político filosófico sobre relações sociais de poder e a educação onde elas se refletem e refratam, e estabelecemos articulações entre o ideário freiriano e de outros pensadores e pensadoras que reconhecemos articuláveis. Com este esforço de complexificação, procuramos não reproduzir Freire mas antes reinventá-lo, respeitando o desejo por ele formulado.

\section{PARA UMA EDUCAÇÃO LIBERTADORA: UMA LEITURA DA EPISTEMOLOGIA FREIREANA}

Na mesma linha de relação entre o trabalho de Freire e as suas experiências de vida, trazemos de novo à colação alguns aspetos do seu percurso que interpretamos à luz da nossa própria experiência e saberes. A tentativa de restaurar uma intersubjetividade humanizadora está inerente à construção deste texto.

Freire cresce num contexto de crise económica mundial e também familiar, ligada à perda do pai. Sofre pobreza, situação que interfere no seu rendimento escolar. Anos depois, é exilado e preso, durante a ditadura, período em que contacta mais profundamente com autores cujas propostas virão a influenciar a sua obra. A sua proximidade à linha de pensamento marxista de Gramsci e neomarxista, na senda de Bourdieu, Bernstein, Bowles e Gintis (TORRES, 1998; SANTOS, 2000), é evidenciada no alerta acerca da força dos constrangimentos da infraestrutura económica e do condicionamento ideológico da superestrutura, presentes na realidade histórico-cultural. Nesta linha, e de forma que se mantém particularmente atual, Freire alerta para os perigos de uma desideologização e para a necessidade de reideologizar:

Talvez nunca antes a classe dominante se tenha sentido tão livre ao exercer a sua prática manipuladora. O pós-modernismo reacionário teve sucesso ao proclamar o desaparecimento de ideologias e a emergência de uma nova história sem classes sociais e, portanto, 
sem interesses antagónicos, sem luta de classes. Afirmam que não há necessidade de continuar a falar em sonhos, utopia ou justiça social (FREIRE, 1996, cit. in APPLE, 1998, p. 39).

A reflexão de Freire foi também provocada pela articulação dialógica com outros pensadores. É a partir de uma matriz de construtivismo social, em ligação com Piaget e Vigotsky (VALE, 1999; GADOTTI, 1997), que Freire desenvolve a sua teorização acerca do papel do sujeito na construção do conhecimento e enfatiza o papel dos contextos e dos processos comunicacionais na sua estruturação. Podemos encontrar esta matriz de influências, por exemplo, na sua conceção de aluno e aluna como sujeitos aprendentes, responsáveis pela coconstrução do conhecimento e pela ressignificação do que aprendem. Esta influência está também patente na sua crítica a uma educação bancária, bem como na argumentação em favor do ensino com base nas condições socioculturais, ideológicas e existenciais do sujeito, no sentido da sua superação, dando resposta à vocação ontológica para ser mais (FREIRE, 1974, 1987). Neste âmbito, aprender

é uma aventura criadora, algo, por isso mesmo, muito mais rico do que meramente repetir a lição dada. Aprender para nós é construir, reconstruir, constatar para mudar, o que não se faz sem abertura ao risco e à aventura do espírito (FREIRE, 1999, p. 77).

O pensamento freiriano apresenta também fortes ligações com a escola de Frankfurt e a Teoria Crítica, na linha de Habermas. Distancia-se das teorias da reprodução social e cultural e situa-se no cerne das teorias da produção social e cultural (MACEDO et al., 2013). É neste âmbito que Freire argumenta em favor da educação enquanto possibilidade histórica de produção cultural, numa relação dialética entre culturas:

defendo uma pedagogia crítico-dialógica (...) a apreensão crítica do conhecimento significativo através da relação dialógica. (...) onde se propõe a construção do conhecimento colectivo, articulando o saber popular e o saber crítico, científico, mediados pelas experiências no mundo (FREIRE, 1999, p. 83).

Na mesma linha, em entrevista, Freire afirma o papel de cada ser humano como autor de mudança:

Eu continuo a dizer, homens e mulheres, não viemos para o mundo para ser treinados, fizemo-nos no mundo seres modificadores. A adaptação ao mundo é apenas um momento do processo histórico. Adapto-me hoje para amanhã, desadaptando-me, corrigir o mundo e inserir-me nele (SERAFIM, 1997, p. 8). 


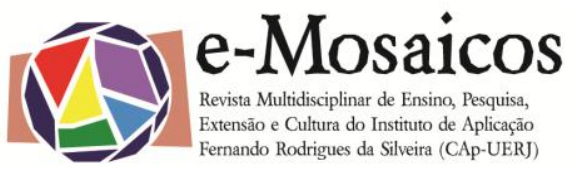

DOI: $10.12957 /$ e-mosaicos.2017.30773

No que concerne a relação do eu com o mundo e no mundo, este autor dialoga também com correntes do existencialismo, cristão e não cristão, (TORRES, 1998; GADOTTI, 1997), fazendo a asserção da incompletude dos seres humanos e da sua permanente construção, num comprometimento indissociável com esse mundo e com o processo de co-laboração humana e humanizante, mediatizado por esse mundo. Nesse enquadramento, Freire refere,

A concepção humanista e libertadora da educação (...) jamais dicotomiza o homem [sic] do mundo. Em lugar de negar, afirma e se baseia na realidade permanentemente mutável. Não só respeita a vocação ontológica do homem de ser mais, como se encaminha para esse objectivo. Estimula a criatividade humana. Tem do saber uma visão crítica; sabe que todo o saber se encontra submetido a condicionamentos histórico-sociológicos. Sabe que não há saber sem busca inquieta, sem a aventura do risco de criar. Reconhece que o homem se faz homem na medida em que, no processo da sua hominização até sua humanização, é capaz de admirar o mundo. (FREIRE, 1974, p. 17).

A pretexto desta citação, faz sentido referir aqui que, no decorrer dos anos 1970, algumas feministas criticaram Freire pelo uso de uma linguagem sexista, em que a palavra 'homem' era utilizada para descrever a humanidade como um todo, incluindo homens e mulheres e ocultando o princípio do "universal neutro". Nele subjaz um sujeito masculino e a invisibilização social das mulheres, que pode servir à manutenção de um poder hegemónico entre homens e mulheres (LISTER, 1997). Reclama-se a "reconstrução de uma marca de cidadania que deixe de privilegiar o masculino através do seu falso universalismo" (LISTER, 1997, p. 12). Como se vê na entrevista de Freire (SERAFIM, 1997), citada mais acima, atento a essas críticas, Freire passou a uma linguagem mais inclusiva, utilizando expressões do tipo "nós, homens e mulheres" ou "aquelas e aqueles educadores". Por outro lado, o modo como veio a reconcetualizar o seu conceito de opressão - inicialmente, apenas em função da classe social -, e a complexificação desse conceito pela inclusão de dimensões como "o racismo e o sexismo" (HORTON e FREIRE, 1990, cit. in WEILER, 2003), denota o peso da influência do pensamento feminista no trabalho deste autor. É talvez por esses motivos que, em anos posteriores e ainda nos nossos dias muitas feministas tomam como ponto de partida ou fazem recurso ao pensamento freiriano, por exemplo, bell hooks ${ }^{3}$ (1994) e Marijke de Koning (2006). Reconhecendo já a pluralidade e complexidade das relações de poder e das suas diversas intersecionalidades, Freire acentua que

não devemos perder de vista a necessidade de reconhecer as diversas construções de poder e autoridade em uma sociedade separada por desigualdades de poder e divisões de privilégio

\footnotetext{
${ }^{3}$ É de notar que Gloria Jean Watkins utiliza o pseudónimo "bell hooks" escrito com letra minúscula por pretender enfatizar o conteúdo da obra e não a pessoa que a escreve.
} 


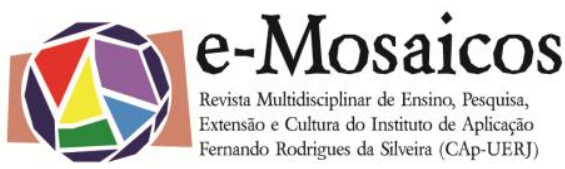

DOI: $10.12957 /$ e-mosaicos.2017.30773

exclusoras, e de como estas estão implicadas nas construções da subjectividade diferenciada por raça, classe e preferência sexual (FREIRE, 1999, p. 15).

Numa perspetiva que enfatiza a não neutralidade da educação, e portanto, o facto de esta ter em conta essas formas de poder diferencial, Freire entende a educação libertadora, em contexto escolar ou não escolar, como corporização de uma práxis reflexiva. Nesta instância, argumentamos com Freire que cabe aos educadores e educadoras progressistas saber em favor "de quê e de quem, portanto contra quê e contra quem" (FREIRE, 1993) fazem educação. Tal exercício de resistência à intimidação não poderá ser desenvolvido num lugar de isolamento nem sem questionarmos as nossas perspetivas e os postos de observação que orientam o nosso olhar. Tal asserção dá lugar à urgência e emergência de processos de deliberação democrática comunicativa valorizadores da diferença (YOUNG, 2002), que tendam à construção de um "pensamento alargado" com o contributo de diversos olhares e portanto mais objetivo (ARENDT, 1958), no sentido mais plural e intersubjetivo (MACEDO, no prelo).

A dificuldade, hoje, num contexto social complexo, é ultrapassar a dualização e os binómios a ela associados para abarcar as múltiplas dimensões do "quê" e do "quem", explorando a sua plasticidade e possíveis entrecruzamentos. Este modo de complexificação é proposto, por exemplo, por autoras como Iris Young (1990) que, numa linha da Teoria Crítica e numa perspetiva de justiça social, explora e atualiza o conceito de "opressão". Reconhecendo nós a proximidade ao pensamento de Freire, inclusivamente por fazer apelo a conceitos similares, Young joga com dimensões de heterogeneidade e reconhecimento e argumenta que diferentes grupos são objeto de diferentes formas de opressão. Nesse sentido,

a opressão nomeia de facto uma família de conceitos e condições (...): exploração, marginalização, falta de poder, imperialismo cultural e violência. (...) a opressão é uma condição de grupos (...) [sendo necessário] examinar o conceito de grupo social (YOUNG, 1990, p. 40).

Para finalizar, partilha-se esta proposta de sistematização da filosofia política da educação de Freire, para uma práxis crítica e reflexiva, conducente à mudança. Lembra-se, com Moacir Gadotti, que o

pensamento de Paulo Freire - a sua teoria do conhecimento - deve ser entendido no contexto em que surgiu - o nordeste brasileiro onde, no início da década de 1960, metade dos seus 30 milhões de habitantes vivia na "cultura do silêncio" - como dizia Freire - eram analfabetos, sendo preciso "dar-lhes a palavra", para que "transitassem" para a participação na construção de um Brasil que fosse dono do seu próprio destino (GADOTTI, 1997, p. 34). 
Enraizando a sua perspetiva de uma educação problematizadora e libertadora a epistemologia freiriana, de que aqui se fez uma leitura, permite acentuar a necessidade de permanente questionamento e atualização da práxis, em linha com as sucessivas atualizações da sua filosofia político-pedagógica que o próprio Paulo Freire foi fazendo ao longo da sua reflexão-ação.

\section{LINHAS CONCLUSIVAS}

Neste artigo, buscámos refletir sobre a proposta político-pedagógica de Freire, em diálogo carinhoso com este autor. Tendo começado por evidenciar 0 reconhecimento social do seu trabalho, passamos a explorar ideias como palavra, diálogo, dialogicidade, práxis e educação libertadora. Afirmamos com Freire a não neutralidade da educação e o seu potencial papel na produção social e cultural numa perspetiva transformadora. Reconhecemos também o papel do posicionamento gnosiológico e político de cada educador e educadora nesse esforço de humanização através da educação, como práxis libertadora.

Atendendo à forte articulação entre a experiência vivida e a obra de Freire, destacamos alguns pontos nodais e evidenciamos pronunciações entre a produção praxiológica deste autor e outras linhas com que este estabeleceu relações, ou nós estabelecemos, à luz do nosso olhar. Situamos Freire como autor da sua - e da nossa - história. Vendo esta como tempo de possibilidade, discutimos como as noções de incompletude, inacabamento, e politicidade, entre outras, constituem condições para a ação transformadora do mundo, num processo de co-laboração problematizadora, que tem que ter em conta os temas geradores universais, inerentes a cada época e espaço sociocultural.

Face ao que aqui foi dito, e ao muito que tem sido dito sobre o trabalho deste educador-político, pode afirmar-se que o trabalho de Freire se enquadra e corporiza um movimento de desafio ao modelo de neutralidade aparente da educação, para debater o poder em termos das classes sociais, e abordar, posteriormente, outras dimensões, como o género, no seu trabalho. Esta enunciação é particularmente premente nos tempos que correm, justificando a sua pertinência, hoje e no futuro.

A obra de Freire permite clarificar o modo como os opressores inculcam valores de submissão nos oprimidos os quais, ao assumirem a sua menoridade de modo naturalizado, acabam por permitir e reforçar a sua manutenção. No entanto, a proposta político-filosófica de educação, na desocultação das desigualdades sociais e no trabalho para a sua transformação, não é isenta de questionamento. Referimos, por exemplo, a sua perspetiva de hominização, homogeneidade e universalidade que merecem uma revisitação, à luz de saberes que nos permitem uma complexificação outra da compreensão da vida social em que o sujeito da cidadania surge fragmentado e reconfigurado, em que se reconhece a intersecionalidade das condições de opressão e em que convivem e por vezes conflituam um conjunto de subjetividades. Estas permitem a construção de visões intersubjetivas das relações 
DOI: $10.12957 /$ e-mosaicos.2017.30773

de poder, necessárias num contexto em que os conceitos de opressão, opressor e oprimido, necessitam também de ser complexificados face à emergência de novas realidades sociais, em que conceitos como estrutura e classe social, surgem hoje como permeáveis e em permanente mudança, desafiando a construção de um saber novo como autores e autoras da nossa história, como defende Freire.

É neste quadro que, passados cinquenta anos sobre a publicação da sua proposta de uma "Pedagogia do Oprimido" ${ }^{4}$, o trabalho de Freire mantém uma força motriz e de enraizamento que nos inspira a uma práxis transformadora sustentada na reinvenção.

\section{REFERÊNCIAS BIBLIOGRÁFICAS}

ALLARD, A. C. Capitalizing on Bourdieu: how useful are concepts of 'social capital' and 'social field' for researching 'marginalized' young women?. Theory and Research in Education, v. 3, n. 1, p. 63-79, 2005.

APPLE, M. Freire, neoliberalismo e educação. In: APPLE, M.; NÓVOA, A. (Org.), Paulo Freire: política e pedagogia. Porto: Porto Editora, 1998.

BOURDIEU, Pierre. The logic of practice. California: Stanford University Press, 1990.

. O poder simbólico. In: GRÁCIO, S. et al., Sociologia da educação II. Lisboa: Livros Horizonte, 1982. p. 101-109.

FREIRE, Paulo. Educação e atualidade brasileira. Recife: Universidade Federal do Recife, 1959.

. Educação como prática da liberdade. Rio de Janeiro: Paz e Terra, 1967.

. Uma educação para a liberdade. Textos Marginais, n. 8, Porto: Dinalivro, 1974. p. 7-21.

. Pedagogia do oprimido (29a Ed.). Rio de Janeiro: Paz e Terra, 1987.

. Política e educação: ensaios. S. Paulo: Cortez, 1993.

FREIRE, P. Pedagogia da autonomia: saberes necessários à prática educativa. São Paulo: Paz e Terra, 1999.

GADOTTI, M. A voz do biógrafo brasileiro: a prática à altura do sonho. Revista da FAEEBA, v. 6, n. 7, jan./jun., p. 33-67, 1997.

\footnotetext{
${ }^{4}$ Contrariamente ao que às vezes se divulga, a Pedagogia do Oprimido não foi o primeiro trabalho de Freire, embora seja um dos mais conhecidos. A sua primeira obra, publicada em (1959) e intitulada Educação e atualidade brasileira foi elaborada como tese de concurso público para a cadeira de História e Filosofia da Educação de Belas-Artes de Pernambuco, sendo editada no Recife, pela Universidade Federal do Recife. Este trabalho viria a ser ainda mais aprofundado na obra Educação como prática da liberdade (1967), que constituiu uma espécie de anúncio da Pedagogia do Oprimido, conforme referia o próprio Freire (MACEDO et al., 2001).
} 
DOI: 10.12957/e-mosaicos.2017.30773

HENRIQUES, F. Da possível fecundidade da racionalidade de Paul Ricoeur para o pensamento feminista. In: FERREIRA, M. L. R. (Org.), Pensar no Feminino. Lisboa: Colibri, 2001. p. 289-295.

HOOKS, B. Teaching to transgress. education as the practice of freedom. New York: Routledge, 1994.

KONING, M. H. Lugares emergentes do sujeito-mulher. viagem com Paulo Freire e Maria de Lourdes Pintasilgo. Porto: Afrontamento, 2006.

LISTER, R. Citizenship: feminist perspectives. New York: New York University Press, 1997.

MACEDO, E. Vozes jovens entre experiência e desejo: que lugares de cidadania?. Porto: Afrontamento (no prelo).

MACEDO, E.; VASCONCELOS, L.; EVANS, M.; LACERDA, M.; VAZ PINTO, M. Revisitando Paulo Freire: sentidos na educação. Brasília: Liber Livro, 2013.

SANTOS, B. S. Os processos da globalização. In: (Org.), Globalização: fatalidade ou utopia?. Porto: Edições Afrontamento, 2001. p. 31-106.

SERAFIM, J. "Nós somos seres de briga": entrevista com o pedagogo Paulo Freire. Cadernos de Educação de Infância, n. 42, abr./jun., p. 4-8, 1997.

STOER, S. R.; MAGALHÃES, A. A diferença somos nós. a gestão da mudança social e as políticas educativas e sociais. Porto: Afrontamento, 2005.

TORRES, C. A. A pedagogia política de Paulo Freire. In: APPLE, M.; NÓVOA, A. (Org.), Paulo Freire: política e pedagogia. Porto: Porto Editora, 1998. p. 47-67.

VALE, M. J. Educação de jovens e adultos: a construção da leitura e da escrita. Cadernos de EJA. São Paulo: IPF, 1999.

WEILER, K. Freire e uma pedagogia feminista da diferença. ex aequo, n. 8, p. 17-45, 2003.

YOUNG, I. Justice and the politics of difference. Princeton: Princeton University Press, 1990. . Inclusion and democracy. Oxford: University Press, 2002.

ZITKOSKI, J. J. Dialogicidade. In: STRECK, D. R.; REDIN, E.; ZITKOSKI, J. J. (Org.), Dicionário Paulo Freire. Rio de Janeiro: Autêntica, 2015. p. 17-18. 